\title{
Plasmin Digestion of Photooxidized Milk Proteins
}

\author{
T. K. Dalsgaard, ${ }^{\star}$ C. W. Heegaard, $†$ and L. B. Larsen ${ }^{\star 1}$ \\ *Department of Food Science, University of Aarhus, Faculty of Agricultural Sciences, PO Box 50, DK-8830 Tjele, Denmark \\ †Protein Chemistry Laboratory, University of Aarhus, 8000 Aarhus C, Denmark
}

\begin{abstract}
Plasmin-mediated hydrolysis of 6 different milk protein preparations $\left[\alpha_{\mathrm{S}}\right.$-casein $\left(\alpha_{\mathrm{S} 1}+\alpha_{\mathrm{S} 2}\right), \beta$-casein, $\kappa$ casein, $\alpha$-lactalbumin, $\beta$-lactoglobulin, and lactoferrin] was found to be very dependent on photooxidation of the said proteins. Changes in plasmin proteolysis were investigated in a peptide-mapping study applying liquid chromatography-mass spectrometry. The changes were seen in the formation of peptides formed by plasmin-mediated hydrolysis after photooxidation, which was initiated with the naturally occurring photosensitizer riboflavin in all the milk protein preparations studied. The changes in the plasmin-mediated hydrolysis of photooxidized proteins are discussed in relation to changes introduced in the protein structure upon photooxidation. Plasmin-mediated hydrolysis of $\alpha_{\mathrm{S}}$-casein, consisting of a mixture of $\alpha_{\mathrm{S}^{-}}$and $\alpha_{\mathrm{S} 2^{-}}$casein and a preparation of $\beta$-casein, was most highly affected by photooxidation, which is in agreement with the fact that those 2 proteins have been found to be most labile toward photooxidation. Changes in the formation of potential angiotensin-I-converting enzyme-inhibitory peptides as well as peptides proposed to have antibactericidal activities by plasmin were observed by oxidation of milk proteins before plasmin-mediated hydrolysis.
\end{abstract}

Key words: photooxidation, plasmin proteolysis, protein oxidation, milk protein

\section{INTRODUCTION}

Enzymatic hydrolysis of proteins has been shown to be dependent on the oxidative status of the substrate proteins (Davies and Goldberg, 1987; Grune et al., 1995). Due to its high relevance in age-related diseases such as Alzheimer's and Parkinson's diseases (Grune, 2000; Stadtman, 2001), enzymatic hydrolysis of oxidized proteins has primarily been investigated in medical science. Several studies have shown that intense oxidation of substrate proteins resulted in decreased

Received November 8, 2007.

Accepted February 25, 2008

${ }^{1}$ Corresponding author: LotteBach.Larsen@agrsci.dk accessibility for proteolytic enzymes, whereas a lower degree of oxidation may actually increase the enzymatic hydrolysis (Grune et al., 2003). The structure of the substrate protein determines the lability of the protein toward oxidation. Thus, in the presence of singlet oxygen, free amino acids have been shown to be more labile than peptides (Michaeli and Feitelson, 1995), and partly unfolded proteins were more labile than intact globular proteins (Michaeli and Feitelson, 1997). It has recently been shown that caseins, having no secondary structures, are more labile toward oxidation than the more compact globular whey proteins (Dalsgaard et al., 2007). Thus, in cheeses, which are exposed to light during manufacture or in the supermarket, protein oxidation may occur, and this may affect cheese shelf life.

Only few studies of the relationship between oxidative modifications and proteolytic degradation in the milk system exist. However, in 1990, Igarashi (Igarashi, 1990) showed that hydrogen peroxide-induced, ascorbic acid-induced, and light-induced oxidation led to a 28 to $38 \%$ increase in proteolysis of $\beta$-casein, as measured by formation of $\gamma$-casein in milk. It was suggested that the increase in proteolysis was caused by oxidative inactivation of plasmin inhibitors (Igarashi, 1990). The increase in proteolysis in oxidized milk was recently confirmed by Wiking and Nielsen (2004), who found that in addition to hydrogen peroxide and light exposure, oxidation induced by $\mathrm{Cu}^{2+}$ also increased proteolysis in milk.

It has been demonstrated that the principal indigenous milk protease plasmin (EC 3.4.21.7) is important for the quality of raw milk (Crudden et al., 2005) as well as for initiation of cheese ripening by hydrolysis of especially $\beta$ - and $\alpha_{\mathrm{S2}}$-casein in Cheddar (Singh et al., 1997), Gouda (Visser and Groot-Mostert, 1977), and Swiss-type cheeses (Ollikainen and Nyberg, 1988). Increase in plasmin activity resulted in reduced curd firmness (Mara et al., 1998), and therefore, plasmin may further play a role during cheese manufacture. Casein-derived peptides have been shown to have different kinds of bioactivities (Silva and Malcata, 2005), and specific peptides from different cheeses have furthermore been shown to have antihypertensive activities or an inhibitory activity for the angiotensin-I-con- 
verting enzyme (ACE; Saito et al., 2000). Because a positively charged amino acid at the C-terminal position has been found to enhance ACE-inhibitory activity of small hydrophobic peptides (Pripp et al., 2004), plasmin hydrolysates make an excellent media for search of ACE-inhibitory activity.

As indicated by the 2 studies mentioned above (Igarashi, 1990; Wiking and Nielsen, 2004), the enzymatic hydrolysis of $\beta$-casein by plasmin may be highly affected by oxidative changes in substrate proteins, and raw milk as well as proteins in cheese may hence be even more hydrolyzed, if the milk proteins are oxidized.

Recently, we investigated photochemical oxidative changes of milk proteins in the presence of the naturally occurring photosensitizer riboflavin (Dalsgaard et al., 2007). Alterations were seen at the primary structural level by introduction of carbonyls and dityrosine, of which the latter also was responsible for cross-linkages. Changes in the tertiary and quaternary protein structures were seen as well, whereas changes at the secondary level were found to be insignificant. Here, we report how these initial photochemical changes affect the proteolytic digestion of the random coil caseins and the 3 globular whey proteins: $\alpha$-lactalbumin, $\beta$-lactoglobulin, and lactoferrin. Plasmin was applied as proteolytic enzyme due to its effect on the quality of raw milk and on cheese ripening.

\section{MATERIALS AND METHODS}

Bovine $\beta$-casein, $\beta$-lactoglobulin, $\alpha_{\mathrm{S}}$-casein $\left(\alpha_{\mathrm{S} 1}+\alpha_{\mathrm{S} 2}\right)$, $\kappa$-casein, $\alpha$-lactalbumin type III, lactoferrin, and bovine plasminogen were supplied from Sigma-Aldrich Chemie GmbH (Steinheim, Germany). Trombolysin (human urokinase) came from Immuno Danmark (Copenhagen, Denmark). Sodium dihydrogen phosphate was obtained from Merck (Darmstadt, Germany). Trifluoroacetic acid (TFA) was from Applichem $\mathrm{GmbH}$ (Darmstadt, Germany). Sodium monohydrogen phosphate was from Baker Analyzed (Deventer, Holland). Acetonitrile (grade S) came from Rathburn Chemicals (Walkerburn, UK). Whatman Mini-UniPrep vials with a pore size of $0.2 \mu \mathrm{m}$ were from Chromtech $\mathrm{GmbH}$ (Idstein, Germany).

\section{Photooxidation of Milk Proteins}

The milk proteins $\alpha_{\mathrm{S}^{-}}\left(\alpha_{\mathrm{S} 1}+\alpha_{\mathrm{S} 2}\right), \beta$-, and $\kappa$-casein; $\alpha$ lactalbumin; $\beta$-lactoglobulin; and lactoferrin were incubated in a concentration of $3 \mathrm{mg} / \mathrm{mL}$ at $10^{\circ} \mathrm{C}$ with 1.75 $\mu \mathrm{g} / \mathrm{mL}$ of riboflavin. The samples were exposed to illumination with fluorescent light for a period of $44 \mathrm{~h}$. The proteins were dissolved in $10 \mathrm{~m} M$ phosphate buffer, $\mathrm{pH}$ 6.8. Control samples with equal amounts of riboflavin were wrapped in aluminum foil to avoid exposure to light and were incubated parallelly. Two other control samples without riboflavin were incubated as well, one wrapped in aluminum foil to avoid exposure to light and one without aluminum foil. All samples were placed in a rotor with a diameter of $30 \mathrm{~cm}$ and a rotation angle of approximately $45^{\circ}$ to the light source (TL-D 90 de Luxe Pro 18W/965 SLV, Philips, Germany), from which they were illuminated with fluorescent light (400 to 600 $\mathrm{nm}$ ), with an intensity of 2,200 to $2,600 \mathrm{~lx}$ depending on the position of the rotor. After photooxidation, the substrates were enzymatically hydrolyzed by plasmin at $30^{\circ} \mathrm{C}$ for $44 \mathrm{~h}$.

\section{Enzymatic Hydrolysis}

Enzymatic hydrolysis was performed by incubating the photooxidized milk proteins at $30^{\circ} \mathrm{C}$ and $\mathrm{pH} 6.8$ in the presence of plasmin. Plasminogen was activated to plasmin by addition of 0.25 unit of thrombolysin/ $\mu \mathrm{g}$ of plasminogen and incubated at $37^{\circ} \mathrm{C}$ for $30 \mathrm{~min}$. The generated plasmin was added to the $\mathrm{pH} 6.8$ aliquots of the different substrate proteins at an enzyme:substrate ratio of $1: 150(\mathrm{wt} / \mathrm{wt})$.

\section{Separation of Peptides in the Plasmin Hydrolysates}

Separation of the peptides formed after enzymatic hydrolysis by plasmin was performed using reversed phase HPLC (RP-HPLC). The hydrolyzed samples were filtered through a $0.2-\mu \mathrm{m}$ filter in a Whatman mini-prep vial and injected onto a reversed-phase C18 column $(218 \mathrm{TP} 5215,15 \times 2 \cdot 1 \mathrm{~mm}$ i.d., 5 - $\mu \mathrm{m}$ particle size) from Vydac (Hesperia, CA). Chromatographic separation of the samples was performed at a constant flow rate of $0.250 \mathrm{~mL} / \mathrm{min}$, and the samples were eluted from the $20^{\circ} \mathrm{C}$ thermostated column by applying a linear gradient of $80 \%$ acetonitrile, $0.1 \%$ TFA as solvent B with the time schedule 2 to $10 \mathrm{~min}: 40 \%, 15 \mathrm{~min}$ : $50 \%$, 45 to 50 min: $100 \%$ of solvent B. Subsequently, the column was equilibrated for 10 min with $0.1 \%$ TFA in water (solvent A) before injection of the next sample. Analyses were performed using an Agilent (Waldbronn, Germany) HPLC series 1100 comprising a model G1312A binary pump, a model G1379A microvacuum degasser, a model G1327A thermostated auto sampler, a model G1316A thermostated column compartment, a model G1315B diode-array detector, and a model G2707DA LC/MSD SL detector fitted with a model G1948A electrospray source. The station was controlled, and the results were analyzed with Agilent's ChemStation software (Rev. A.10.02), including a deconvolution feature that allows prediction of masses for higher molecular weight peptides. The UV spectra were 
recorded at 214 and $280 \mathrm{~nm}$ with a bandwidth of $4 \mathrm{~nm}$ and a reference at $600 \mathrm{~nm}$. The MS spectra of samples were recorded in SCAN (from mass:charge 50 to 3,000) and positive modes. The RP-HPLC separations were repeated in duplicate at 3 different fragmentor voltages, 70,120 , and $250 \mathrm{~V}$, respectively, with a gain of 1.0 electron multiplier voltage and step size 0.20 . Nitrogen was used as a drying gas at a flow rate of $13 \mathrm{~L} / \mathrm{min}$ and as a nebulizing gas at a pressure of $60 \mathrm{psig}(413.7 \mathrm{kPa})$ and a temperature of $300^{\circ} \mathrm{C}$. A potential of $3,000 \mathrm{~V}$ was used on the capillary.

\section{Peptide Mapping}

Peptide mapping was performed by applying the UV $(214 \mathrm{~nm})$ and MS signals from the RP-HPLC separation. The formed peptides were identified by comparing the masses detected in the MS signal with those theoretically calculated by using the bioinformatics tool boxes available at the ExPASy Proteomic Server (http:// us.expasy.org/). Theoretically calculated trypsin hydrolysates of each of the substrate proteins were compared with the empirically identified masses of the peptides isolated in the plasmin digest.

\section{RESULTS AND DISCUSSION}

The 6 milk proteins, $\alpha_{\mathrm{S}}$-casein, $\beta$-casein, $\kappa$-casein, $\alpha$-lactoglobulin, $\beta$-lactoglobulin, and lactoferrin, were applied as substrate for the indigenous milk protease plasmin. The 6 milk proteins were all enzymatically hydrolyzed after $44 \mathrm{~h}$ of photooxidation, and the chromatographic profiles obtained for the hydrolysates of the photooxidized protein were compared with hydrolysates from the nonoxidized controls (Figure 1). The peptide profiles for $\alpha_{\mathrm{S}}$-casein, $\beta$-casein, and $\alpha$-lactalbumin were extensively modified, when the substrate proteins had been oxidatively modified for $44 \mathrm{~h}$, whereas the enzymatic hydrolysis of oxidized $\kappa$-casein was only slightly modified after oxidation. Changes were also seen in the accessibility for plasmin after photooxidation of $\beta$-lactoglobulin and lactoferrin.

Some of the decreases in peptide formation may be due to oxidation-induced aggregation and precipitation of the proteins. However, the total sum of UV absorption in the chromatogram obtained for the native and oxidized protein hydrolysates generated with plasmin was essentially the same, and this indicates that precipitations due to photooxidation did not occur in significant amounts.

After plasmin-mediated hydrolysis of $\alpha_{\mathrm{S}}$-casein $\left(\alpha_{\mathrm{S} 1}\right.$ $\left.+\alpha_{\mathrm{S} 2}\right), 26$ distinct peaks were observed to differ between the oxidized and nonoxidized samples (Figure 1A). Most of the peaks seen in the chromatograms decreased as

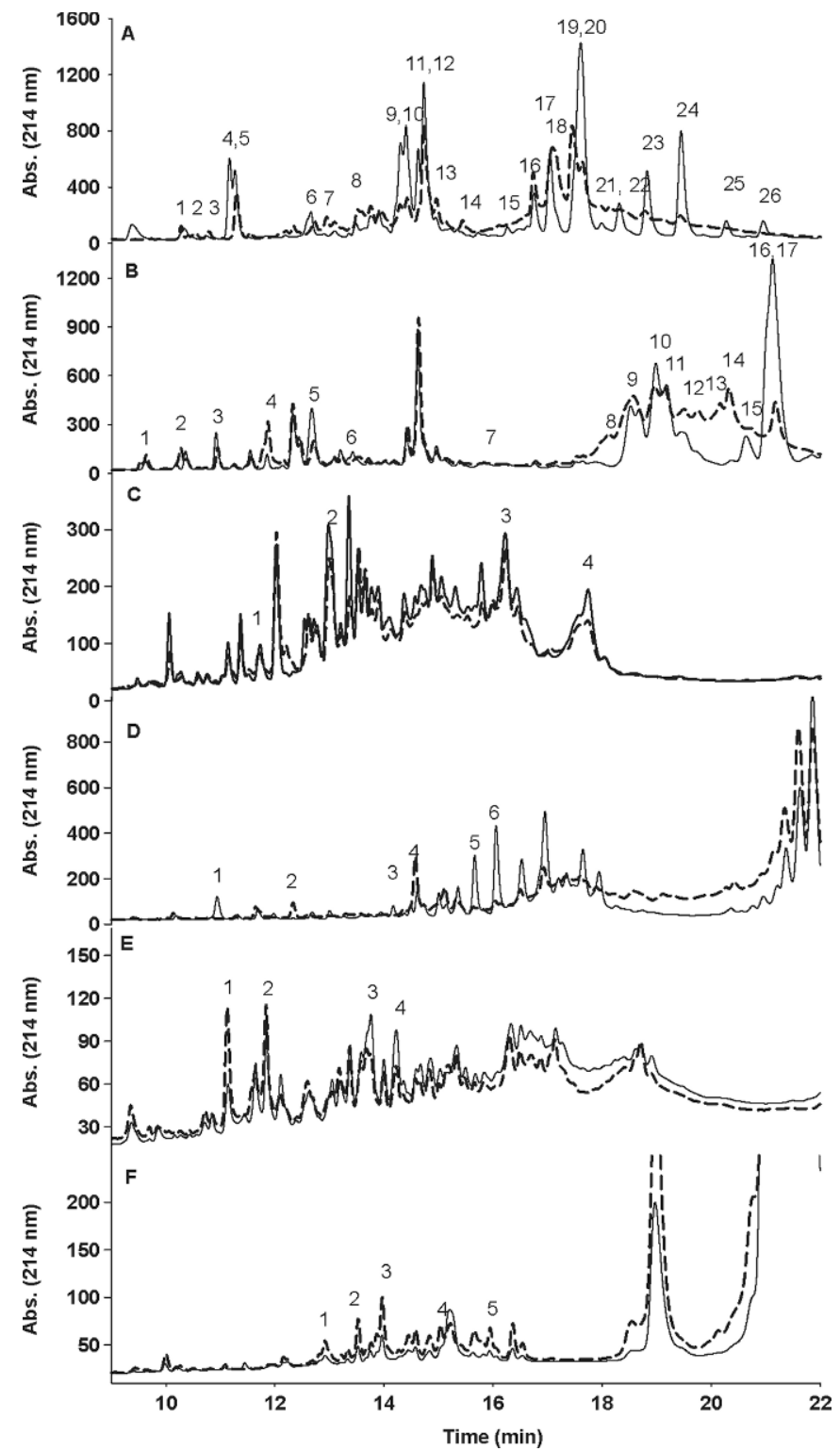

Figure 1. Chromatograms obtained by reverse phase HPLC with UV detection at $214 \mathrm{~nm}$ of peptides after plasmin photooxidized (-- ) or nonoxidized ( - ) proteins. Peptides from A) $\alpha$-casein, B) $\beta$-casein, C) $\kappa$-casein, D) $\alpha$-lactalbumin, E) $\beta$-lactoglobulin, and F) lactoferrin. Photooxidized proteins (44 $\mathrm{h}$ at 2,200 to 2,600 $\mathrm{lx}$ ) and controls that had not been exposed to light were hydrolyzed by plasmin for $44 \mathrm{~h}$ at $30^{\circ} \mathrm{C}$ in an enzyme:substrate ratio (mass ratio) of 1:150 at $\mathrm{pH}$ 6.8. $\mathrm{Abs}=$ absorption.

a result of oxidation, but increases were seen as well. Particularly in the region of 15 to 22 min of retention time, the peaks became less well-defined after oxidation of $\alpha_{\mathrm{S}}$-casein.

The changes in the proteolytic profiles after oxidation of $\beta$-casein were not as large as those seen for $\alpha_{\mathrm{S}}$-casein (Figure 1B). The most significant differences were observed at the retention time 17 to $22 \mathrm{~min}$, in which the 
peaks in the oxidized samples became less well-defined. Among the caseins, it was clear that plasmin-mediated hydrolysis of $\kappa$-casein was least affected by oxidation (Figure 1C). Even though several peptides were seen in the chromatograms obtained by the RP-HPLC separation, only $4 \kappa$-casein-derived peptides could be identified based on their theoretically calculated masses. Previously, $\kappa$-casein has been shown to be almost nondigestible by plasmin (Eigel, 1977), but using the relatively long incubation period of $44 \mathrm{~h}$, we observed extensive hydrolysis of $\kappa$-casein. None of the whey proteins were completely hydrolyzed by plasmin. However, $\alpha$-lactalbumin was the whey protein that was most susceptible to hydrolysis by plasmin. The other 2 whey proteins, $\beta$-lactoglobulin and lactoferrin, also produced a variety of peptides, albeit in relatively low quantities.

Peptides could be identified in the structure of $\alpha$ lactalbumin in 6 out of 10 peaks that differed before and after oxidation of the protein, and most of these peptides showed a marked decrease after oxidation. As for $\alpha_{\mathrm{S}^{-}}$and $\beta$-casein, some less well-defined peaks accumulated between 17 and 22 min of retention time after photooxidation of $\alpha$-lactalbumin (Figure 1D). After oxidation of $\beta$-lactoglobulin, 5 peptides were identified upon hydrolysis by plasmin, 3 of which decreased and 2 increased compared with the nonoxidized species (Figure $1 \mathrm{E}$ ). More peaks varied, but they could not be identified according to the calculated masses from the primary structure of $\beta$-lactoglobulin. In plasmin-mediated hydrolysis of lactoferrin, 5 peptides, which all increased after oxidation, were identified (Figure 1F).

Assuming that the variation (decrease or increase) in absorbance at $214 \mathrm{~nm}$ is proportional to the peptide amount when comparing corresponding peaks from native and oxidized samples, we deduced that the observed peak variations obtained among oxidized and native species rely on a diverse accessibility for plasmin. The resulting peptides generated from plasminmediated hydrolysis of the oxidized milk proteins were listed according to their UV signal as well as to their masses measured by MS as shown in Table 1. All the peptides, whose formation was suggested to be affected by oxidation and which were identified by MS, are listed in Table 1 . The intensity changes found when comparing the nonoxidized with the oxidized plasmin-mediated hydrolysates were observed both in the UV measurements as well as in the MS measurements. In the following, the explanations refer to the last column in Table 1.

Due to structural changes that have recently been reported after photooxidation of the same proteins (Dalsgaard et al., 2007), the following explanations have been put forward in an attempt to explain the variation in the chromatogram when comparing native and oxi- dized samples of model protein preparation: 1 ) reduced accessibility for plasmin to the peptide bond in question due to conformational changes in the substrate proteins induced by oxidation and 2) increased accessibility for plasmin due to conformational changes induced by oxidation. In both 1 and 2 , the conformational changes induced by oxidation of amino acid residues may induce changes at the tertiary or quaternary structural levels. Changes at the quaternary level may be the result of cross-linking between 2 tyrosine residues (dityrosine). The last 2 explanations are as follows: 3 ) decreases in formation of a methionine-containing peptide, which upon oxidation would change the retention time, and 4) increases in the formation of peptides containing oxidized methionine, in which the formation of oxidized methionine in the sequence was confirmed by mass spectrometry. Oxidative modification of methionine would be expected to change the retention time of the peptide of concern and therefore to induce decreases or increases in the resulting peaks in the chromatogram (Figure 1).

Decreased accessibility for the protease due to oxidatively induced structural changes (explanation 1) may hence account for the decrease seen for the 10 plasminderived $\alpha_{\mathrm{S}}$-casein peptides present in the 8 peaks (A3, $\mathrm{A} 5, \mathrm{~A} 6, \mathrm{~A} 9, \mathrm{~A} 12, \mathrm{~A} 24, \mathrm{~A} 25$, and A26). Two peptides were identified in peak A3 and A9, respectively. Increases in the formation of 14 of the peptides identified in peaks $\mathrm{A} 1, \mathrm{~A} 2, \mathrm{~A} 8, \mathrm{~A} 13, \mathrm{~A} 14, \mathrm{~A} 15, \mathrm{~A} 16, \mathrm{~A} 17, \mathrm{~A} 18, \mathrm{~A} 19$, and A22 were seen after photooxidation, and these increases could be explained by a higher accessibility for the enzyme after photooxidation (explanation 2). The accessibility for plasmin to many of its principal cleaving sites $\left(\mathrm{Lys}_{21}-\mathrm{Gln}_{22}, \mathrm{Lys}_{24}-\mathrm{Asn}_{25}, \mathrm{Arg}_{114}-\mathrm{Asn}_{115}, \mathrm{Lys}_{149}-\mathrm{Lys}_{150}\right.$, Lys $_{150}-\mathrm{Thr}_{151}, \mathrm{Lys}_{181^{-}}-\mathrm{Thr}_{182}, \mathrm{Lys}_{188^{-}}-\mathrm{Ala}_{189}$, and Lys ${ }_{197^{-}}$ $\left.\mathrm{Thr}_{198}\right)$ in $\alpha_{\mathrm{S} 2}$-casein, which have previously been described by (Visser et al., 1989) and (LeBars and Gripon, 1989), may have changed after oxidation. The cleavage site $\mathrm{Lys}_{24}-\mathrm{Asn}_{25}$ was identified by formation of the peptide $\mathrm{Lys}_{1}-\mathrm{Lys}_{24}$ seen in peak A22. The cleavage site $\operatorname{Arg}_{114}-\mathrm{Arg}_{115}$ was seen for the other peptide Phe ${ }_{92^{-}}$ $\mathrm{Arg}_{114}$ found in peak A22. The cleavage site $\mathrm{Lys}_{149^{-}}$ Lys $_{150}$ was essential for the formation of a variety of peptides, that is $\mathrm{Glu}_{126}$ - $^{-\mathrm{Ls}_{149}}$ found in peak A6, Lys $150^{-}$ $\mathrm{Lys}_{160}$ in peak A8, $\mathrm{Lys}_{150^{-}} \mathrm{Arg}_{158}$ in peak A16, and $\mathrm{Thr}_{138^{-}}$ Lys $_{149}$ in peak A20. The cleavage of $\alpha_{\mathrm{S2}^{2}}$-casein at $\mathrm{Lys}_{181^{-}}$ $\mathrm{Thr}_{182}$ was observed as a formation of the 2 peptides $\mathrm{Thr}_{182}$-Lys 188 in peak A1 and $\mathrm{Phe}_{174}$-Lys $_{181}$ in peak A13. The cleavage site $\mathrm{Lys}_{188}-\mathrm{Ala}_{189}$ was seen in the formation of the 2 peptides, $\mathrm{Thr}_{182} \mathrm{Lys}_{188}$ in peak A1 and $\mathrm{Ala}_{189}-\mathrm{Lys}_{197}$ in peaks A7 and A8 holding oxidized and nonoxidized methionine, respectively. The peptide $\mathrm{Ala}_{189}$-Lys $_{197}$, which increased after oxidation, has previously been found to hold ACE-inhibitory activity 
Table 1. Peptides identified from their UV absorption and their masses after $44 \mathrm{~h}$ of photooxidation and subsequent $44 \mathrm{~h}$ of plasmin hydrolysis at $\mathrm{pH} 6.8$ in darkness

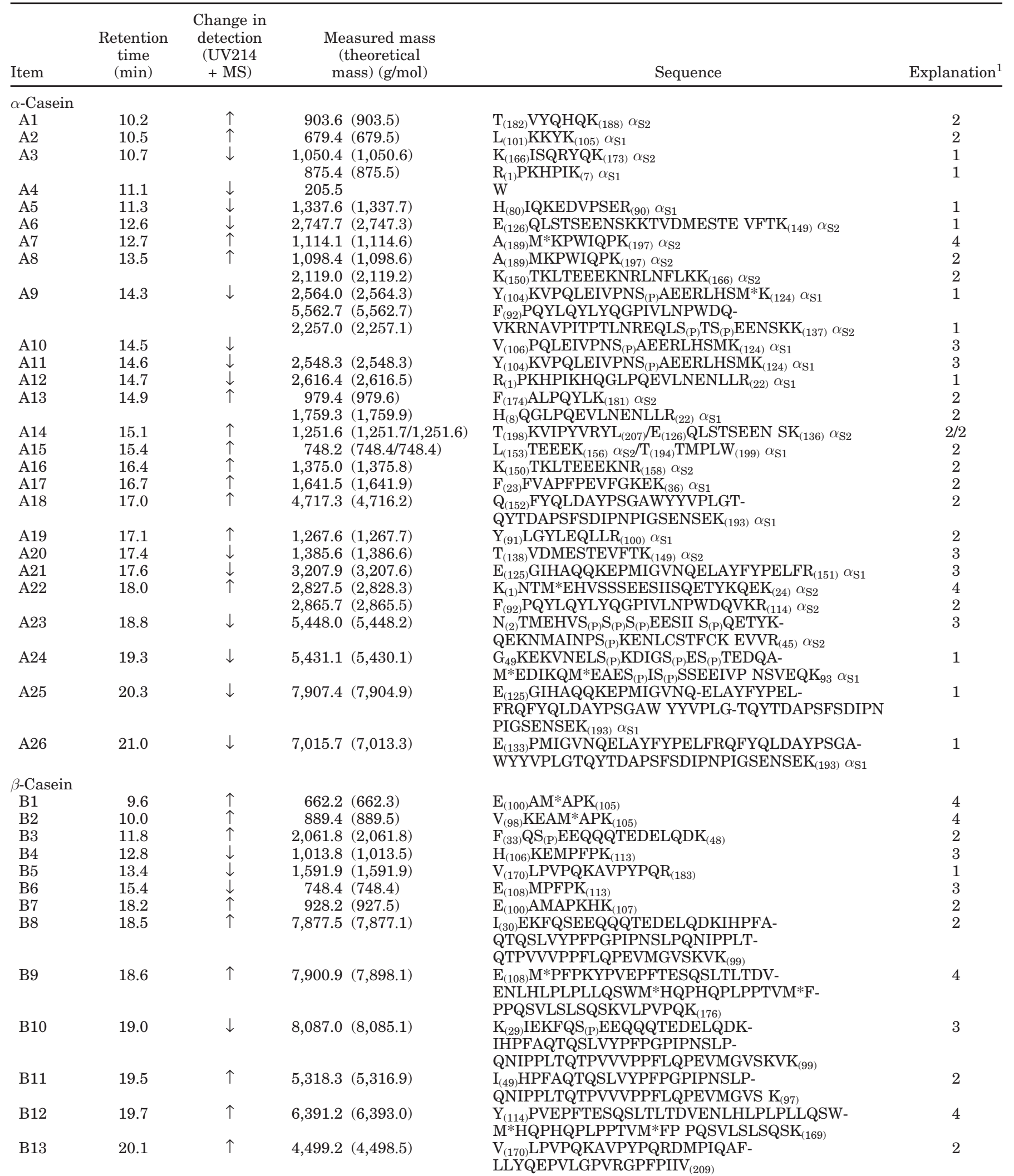


Table 1 (Continued). Peptides identified from their UV absorption and their masses after $44 \mathrm{~h}$ of photooxidation and subsequent $44 \mathrm{~h}$ of plasmin hydrolysis at $\mathrm{pH} 6.8$ in darkness

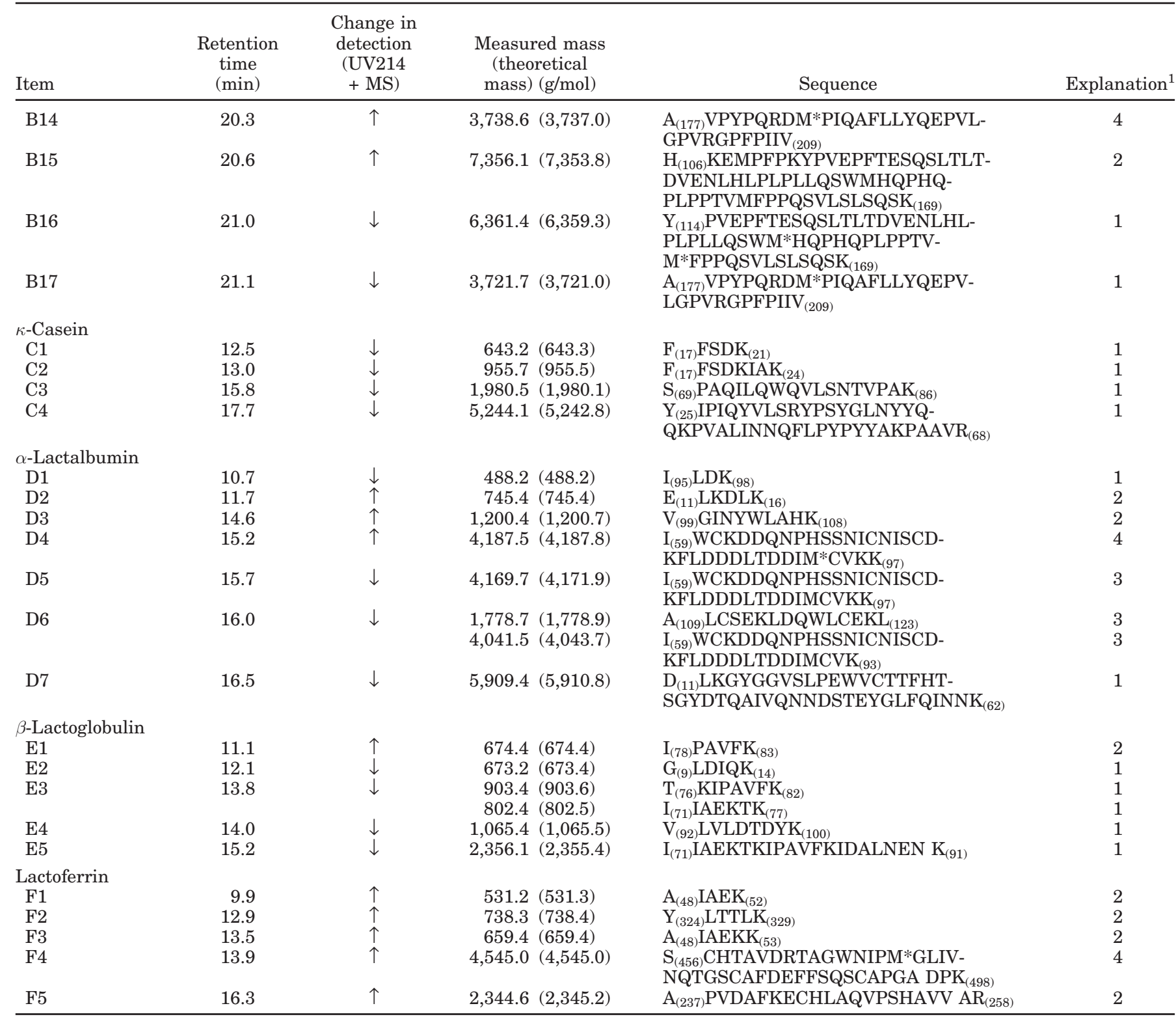

${ }^{1}$ The numbers in the last column refer to $1=$ reduced accessibility; $2=$ increased accessibility; $3=$ reduction due to methionine oxidation; 4 = increment due to methionine oxidation; * refers to methionine oxidation confirmed by MS, (P) refers to phosphorylation.

(Maeno et al., 1996). A C-terminal peptide of $\alpha_{\mathrm{S2}}$-casein $\left(\mathrm{Thr}_{198}-\mathrm{Leu}_{207}\right)$, which was found to increase after photooxidation, was identified in peak A14. This C-terminal peptide from $\alpha_{\mathrm{S} 2}$-casein has formerly been proposed to be important for taste due to a potentially bitter flavor (LeBars and Gripon, 1989). The bitter peptide identified by Le Bars and Gripon (1989) had a longer sequence than the one identified in this study. This may, however, reflect the longer period ( $44 \mathrm{~h}$ versus 2 h) of plasmin incubation used in the present study.
The specific cleavage sites of plasmin in $\alpha_{\mathrm{S} 1}$-casein were investigated in a study by McSweeney et al. (1993). Plasmin was found to cleave $\alpha_{\mathrm{S1}^{-}}$-casein at $\mathrm{Arg}_{22^{-}}$ $\mathrm{Phe}_{23}, \mathrm{Arg}_{90}-\mathrm{Tyr}_{91}, \mathrm{Lys}_{102}-\mathrm{Lys}_{103}, \mathrm{Lys}_{103}-\mathrm{Tyr}_{104}, \mathrm{Lys}_{105^{-}}$ $\mathrm{Val}_{106}, \mathrm{Lys}_{124}-\mathrm{Glu}_{125}$, and $\mathrm{Arg}_{151}-\mathrm{Gln}_{152}$ (McSweeney et al., 1993). The cleavage of $\alpha_{\mathrm{S}_{1}}$-casein at $\mathrm{Arg}_{22}-\mathrm{Phe}_{23}$, found to be a principal cleavage site for plasmin (McSweeney et al., 1993), is essential for the formation of $\mathrm{Arg}_{1}-\mathrm{Arg}_{22}$ (in peak A12), $\mathrm{His}_{8}-\mathrm{Arg}_{22}$ (in peak A13), and $\mathrm{Phe}_{23}$-Lys 36 (in peak A17). The difference in the 
formation of the peptide $\mathrm{Arg}_{1}-\mathrm{Arg}_{22}$ (peak A12) indicated that the cleavage of the peptide bond $\mathrm{Arg}_{22}-\mathrm{Phe}_{23}$ was negatively affected by oxidation. However, an increased formation of the peptide $\mathrm{His}_{8}$ - $\mathrm{Arg}_{22}$ after oxidation suggested that the cleavage site at $\mathrm{Lys}_{7}-\mathrm{His}_{8}$ became more exposed after oxidation, which may account for the reduction in the formation of the longer peptide $\mathrm{Arg}_{1}-\mathrm{Arg}_{22}$. A peptide that was 1 residue longer $\left(\mathrm{Arg}_{1-}\right.$ $\mathrm{Phe}_{23}$ ) has previously been shown to have antimicrobial activity (Lahov and Regelson, 1996), and the suggested further cleavage of the peptide $\mathrm{Arg}_{1}-\mathrm{Arg}_{22}$ at the $\mathrm{Lys}_{7}{ }^{-}$ $\mathrm{His}_{8}$ bond may have a negative effect on this activity. The cleavage of the peptide bond $\mathrm{Arg}_{90}-\mathrm{Tyr}_{91}$ was identified for 1 decreasing peptide $\left(\mathrm{His}_{80}\right.$ - $\left.\mathrm{Arg}_{90}\right)$ identified in peak A5 and 1 increasing peptide $\left(\mathrm{Tyr}_{91}-\mathrm{Arg}_{100}\right)$ observed in peak A19. Cleavage of the peptide bond $\mathrm{Lys}_{103^{-}}$ $\mathrm{Tyr}_{104}$ was essential for the formation of the peptide $\mathrm{Tyr}_{104}-\mathrm{Lys}_{124}$ observed with oxidized and nonoxidized methionine in peaks A9 and A11, respectively. The formation of the peptide $\mathrm{Val}_{106}-\mathrm{Lys}_{124}$ present in peak A10 identified the cleavage of the peptide bond $\mathrm{Lys}_{105}-\mathrm{Val}_{106}$. Cleavage of the peptide bond $\mathrm{Lys}_{124}$-Glu $_{125}$ was involved in the formation of the peptide $\mathrm{Val}_{106}-\mathrm{Lys}_{124}$ (in peak $\mathrm{A10}$ ), $\mathrm{Tyr}_{104}$-Lys ${ }_{124}$ (in peak A11), and $\mathrm{Glu}_{125}-\mathrm{Arg}_{151}$ (in peak A21), whereas the cleavage of $\mathrm{Arg}_{151}-\mathrm{Gln}_{152}$ was essential for the formation of the 2 peptides $\mathrm{Gln}_{152^{-}}$ Lys $_{193}$ (peak A18) and Glu $125-\mathrm{Arg}_{151}$ (peak A21). Formation of the peptide $\mathrm{Gln}_{152}$-Lys ${ }_{193}$ increased as a consequence of conformational changes and thereby increased accessibility for the protease (explanation 2), and the formation of the peptide $\mathrm{Glu}_{125}-\mathrm{Arg}_{151}$ decreased because of oxidation of a methionine residue (explanation 3). Peak A15 may hold the peptide $\mathrm{Thr}_{194^{-}}$ Trp 199 , which has been shown to have ACE-inhibitory activity (Pihlanto-Leppala et al., 1998). The peptide bond $\operatorname{Lys}_{102}-\mathrm{Lys}_{103}$ was the only specific cleavage site of plasmin detected by McSweeney et al. (1993) that was not involved in the formation of peptides that became affected by the oxidation of $\alpha_{\mathrm{S} 1}$-casein. Some of the changes seen in the chromatogram when comparing the oxidized hydrolysates with the nonoxidized hydrolysate of $\alpha_{\mathrm{s} 1}$-casein were caused by methionine oxidation. Hence, due to the presence of methionine in the sequence of 5 other peptides present in peaks A10, A11, $\mathrm{A} 20, \mathrm{~A} 21$, and A23, a decreased formation of these peptides could be explained by methionine oxidation (explanation 3). A single distinct peak in the chromatogram (A7) obtained for oxidized $\alpha_{\mathrm{S} 2}$-casein indicated formation of a new peptide, wherein the methionine became oxidized (explanation 4). Overall, the mixture of $\alpha_{\mathrm{S} 1}$ and $\alpha_{\mathrm{S} 2}$ caseins seemed to be more efficiently hydrolyzed after oxidation, as evidenced by the observed decrease in peptide masses shown in the oxidized hydrolysate (679.4 to $2,867.7$ mass:charge) relative to the mass distribution found in the native hydrolysate (874.4 to 7,907.4 mass:charge). Increased proteolytic degradation of oxidized proteins has been correlated by unfolding and increased hydrophobicity of the substrate protein after oxidation (Giulivi et al., 1994), and unfolding of the oxidized protein may account for the formation of lower molecular weight peptides. This tendency was not seen for $\beta$-casein, in which higher molecular mass peptides were formed after oxidation, indicating a less efficient hydrolysis of $\beta$-casein after oxidation.

In earlier investigations, the influence of oxidation upon proteolysis of milk proteins was measured as changes in the formation of trichloroacetic acid precipitable $\gamma$-caseins ( $\mathrm{Lys}_{29}-\mathrm{Val}_{209}$; Igarashi, 1990), a hydrolysis product of $\beta$-casein, or simply by measuring the changes in the formation of free $\mathrm{N}$-terminals (Wiking and Nielsen, 2004). Both methods revealed a positive relation between substrate hydrolysis and substrate photooxidation. In this study, the generated peptides were identified, thus giving a more detailed view of how photooxidation of different milk proteins affected the enzymatic hydrolysis by plasmin. In addition to the previous studies, we disclose a more complex picture, in which both decreased and increased formation of peptides resulted from photooxidation.

All the peptides produced after plasmin-mediated hydrolysis of oxidized and nonoxidized $\beta$-casein were identified in the primary structure of $\beta$-casein. The variations in peptides produced by plasmin-mediated hydrolysis of $\beta$-casein before and after photooxidation were explained in the same way as those evaluated above for $\alpha$-casein (Table 1). A decrease was seen in the formation of 3 peptides (in peaks B5, B16, and B17) after photooxidation, and this decrease was explained by structural changes induced by photooxiation. Tyrosine was present in the sequence of the identified peptides, and hence, changes in quaternary protein structure due to formation of dityrosine (Dalsgaard et al., 2007) may be the reason for the observed decrease. The reduction could be explained by cross-linkages that led to decreased accessibility for plasmin (explanation 1). An increased amount was seen for 6 peptides (in peaks B3, B7, B8, B11, B13, and B15) after photooxidation, and the increase of these peptides could be explained by structural changes, which were due to oxidation, and they led to increased susceptibility for hydrolysis by plasmin (explanation 2). The large $\gamma^{1}$-casein ( Lys $_{29^{-}}$ $\mathrm{Val}_{209}$ ) was not identified in the chromatogram obtained for the plasmin-mediated hydrolysis of $\beta$-casein in this study. Further cleavage of this compound $\left(\mathrm{Lys}_{29}-\mathrm{Val}_{209}\right)$ into $\gamma^{2}$-casein (that corresponds to the cleavage at Lys $_{105}$-His 106 seen in peak B15); $\gamma^{3}-, \gamma^{4}$-, and $\gamma^{5}$-caseins; or fragments of those that might have been produced 
due to the long time of incubation with plasmin ( $44 \mathrm{~h})$ was identified in peaks B4, B9, B12, and B17. However, as mentioned above, higher molecular mass peptides were produced more efficiently after oxidation. This indicates less accessibility for plasmin after oxidation and, specially, the region $\left(\mathrm{Glu}_{108}-\mathrm{Val}_{209}\right)$, which has previously been shown to produce small bioactive peptides with ACE-inhibitory activity (Maruyama et al., 1987; Maeno et al., 1996; Pihlanto-Leppala et al., 1998; Silva et al., 2006), seemed to be hydrolyzed less efficiently by plasmin after oxidation. Methionine oxidation could be responsible for the changes observed for 8 peptides. Three decreasing peptides were identified in B4, B6, and B10. The decrease was explained by methionine oxidation (explanation 3), and the increase observed in 5 peaks (peak B1, B2, B9, B12, and B14) was explained by explanation 4 .

Four peptides varying in the chromatogram obtained from plasmin digest of nonoxidized and oxidized $\kappa$-casein were identified by the MS signal (Table 1). The decrease observed after photooxidation for all of the 4 peptides identified in peaks $\mathrm{C} 1, \mathrm{C} 2, \mathrm{C} 3$, and $\mathrm{C} 4$, respectively, was explained by decreased accessibility (explanation 1). Three peptides in peaks C1, C2, and C3 were explained by decreased accessibility (explanation 2). Unfortunately, we were unable to identify any $\kappa$-casein peptides in the peak with a retention time of $13.4 \mathrm{~min}$, which was the one showing the highest decrease as a result of photooxidation and subsequent enzymatic hydrolysis.

$\alpha$-Lactalbumin was the globular protein showing the largest changes in the peptide profile after photooxidation and subsequent hydrolysis by plasmin (Table 1). Broader peaks were seen after oxidation of $\alpha$-lactalbumin. We have previously reported that the formation of dityrosine was highest in the random coil proteins $\alpha_{\mathrm{S}^{-}}$ and $\beta$-caseins in model systems investigating structural changes after oxidation of the same proteins as used in the present study, whereas $\alpha$-lactalbumin was the globular protein showing the highest content of dityrosine after $44 \mathrm{~h}$ of photooxidation (Dalsgaard et al., 2007). Thus, the broader peaks observed in the present study may reflect formation of cross-linkages, making the separation of the produced cross-linked peptides more difficult. Seven different peptides were identified in the digest of $\alpha$-lactalbumin. Decreased accessibility (explanation 1) may be the explanation for the peptide identified in peak D1 and peak D7, whereas the amount of 2 additional peptides present in peaks D2 and D3 increased, and this was probably due to a higher accessibility for plasmin after photooxidation (explanation 2). $\alpha$-Lactalbumin was the globular protein showing the highest degree of unfolding after photooxidation, as measured by tryptophan excitation (Dalsgaard et al.,
2007). Hence, the observed decrease in the formation of peptides, as indicated by the chromatographic profile of plasmin-hydrolyzed $\alpha$-lactalbumin after oxidation, may well be due to changes in accessibility for the enzyme caused by conformational changes and by crosslinkages. Partly unfolding of proteins has, however, been shown to enhance the accessibility for other proteases, in which cross-linkages in the substrate proteins have been suggested to decrease the accessibility for the proteases (Giulivi et al., 1994). Therefore, the high content of dityrosine in $\alpha$-lactalbumin (Dalsgaard et al., 2007) may be decisive for the changes observed after photooxidation in the $\alpha$-lactalbumin peptide map in this study, whereas the partly unfolding of $\alpha$-lactalbumin may be of less importance for the accessibility of $\alpha$ lactalbumin for plasmin. The altered appearance of 3 peptides may be dedicated to oxidation of methionine; 2 peptides identified in D5 and D6 decreased, and 1 peptide in D4 increased after successive photooxidation and plasmin-mediated hydrolysis.

From the plasmin-mediated hydrolysis of $\beta$-lactoglobulin, 6 varying peptides could be identified according to the masses obtained by MS (Table 1 ). The formation of 1 peptide present in peak E1 increased due to a higher accessibility for the enzyme to the cleaving sites after oxidation. Five peaks decreased, and the decrease in the formation of the peptide identified in peaks E2, E3, E4, and E5 could be explained by lower accessibility for the enzyme after oxidation (explanation 1).

In the plasmin-mediated hydrolysis of lactoferrin, an increase in 5 peptides identified in the peaks (F1 to F5) was observed following oxidation. The build-up of 4 of the peptides present in peaks F1, F2, F3, and F5 could be explained by increased accessibility for plasmin after photooxidation (explanation 2), whereas 1 peptide identified in peak F4 probably increased due to oxidation of methionine (Table 1). In the chromatogram, a double peak with high intensity, which increased after oxidation, was seen with a retention time of approximately 18.6 and $19.0 \mathrm{~min}$, respectively. According to the UV absorption, peptides were definitely present in the double peak, but they were not ionizable by the applied electro spray.

Changes seen in the formation of peptides from the whey proteins may be of relevance for the production of peptides with antibacterial effect as well as with ACE-inhibiting effects. The peptide $\left(\mathrm{Val}_{99}-\mathrm{Lys}_{108}\right)$ from $\alpha$-lactalbumin (identified in peak D3) has thus formerly been shown to be able to inhibit ACE (Pihlanto-Leppala et al., 2000). The formation of this peptide was found to increase after oxidation. Also, the quantity of the ACE inhibitor ( $\mathrm{Gly}_{9}-\mathrm{Lys}_{16}$ ) obtained from $\beta$-lactoglobulin (E2; Pihlanto-Leppala et al., 1998) increased after oxidation of $\beta$-lactoglobulin. Two other peptides pro- 
duced by plasmin digest of $\beta$-lactoglobulin have been proposed to have bactericidal activity (Pellegrini et al., 2001). The formation of one of these peptides (Ile ${ }_{78^{-}}$ $\mathrm{Lys}_{83}$; identified in peak E1) increased after oxidation, whereas the formation of the other peptide $\left(\mathrm{Val}_{92^{-}}\right.$ Lys $_{100}$; identified in peak E4) decreased when $\beta$-lactoglobulin was oxidized before plasmin-mediated hydrolysis.

\section{CONCLUSIONS}

In conclusion, it was shown that plasmin-mediated hydrolysis of different milk proteins is affected by changes induced in the substrate proteins after photooxidation. Both $\alpha$ - and $\beta$-caseins have previously been shown to be highly influenced by photooxidation, and significant changes in the proteolytic profiles by plasmin of especially these proteins were shown to occur after photooxidation. Among the whey proteins studied, $\alpha$-lactalbumin showed the most significant changes in the proteolytic profile after photooxidation. The changes observed in the peptide profiles of the plasmindigested milk proteins after photooxidation included changes in formation of both bioactive and bitter peptides.

\section{REFERENCES}

Crudden, A., P. F. Fox, and A. L. Kelly. 2005. Factors affecting the hydrolytic action of plasmin in milk. Int. Dairy J. 15:305-313.

Dalsgaard, T. K., D. E. Otzen, J. H. Nielsen, and L. B. Larsen. 2007. Changes in structures of milk proteins upon photo-oxidation. J. Agric. Food Chem. 55:10968-10976.

Davies, K. J. A., and A. L. Goldberg. 1987. Proteins damaged by oxygen radicals are rapidly degraded in extracts of red blood cells. J. Biol. Chem. 262:8227-8234.

Eigel, W. N. 1977. Effect of bovine plasmin on alpha-S1-B and kappaA caseins. J. Dairy Sci. 60:1399-1403.

Giulivi, C., R. E. Pacifici, and K. J. A. Davies. 1994. Exposure of hydrophobic moieties promotes the selective degradation of hydrogen peroxide-modified hemoglobin by the multicatalytic proteinase complex, proteasome. Arch. Biochem. Biophys. 311:329-341.

Grune, T. 2000. Oxidative stress, aging and the proteasomal system. Biogerontology 1:31-40.

Grune, T., K. Merker, G. Sandig, and K. J. A. Davies. 2003. Selective degradation of oxidatively modified protein substrates by the proteasome. Biochem. Biophys. Res. Commun. 305:709-718.

Grune, T., T. Reinheckel, M. Joshi, and K. J. A. Davies. 1995. Proteolysis in cultured liver epithelial cells during oxidative stress-Role of the multicatalytic proteinase complex, proteasome. J. Biol. Chem. 270:2344-2351.

Igarashi, Y. 1990. Enhancement of proteolysis in bovine skim milk by heat and chemical treatments. J. Dairy Res. 57:541-548.
Lahov, E., and W. Regelson. 1996. Antibacterial and immunostimulating casein-derived substances from milk: Casecidin, isracidin peptides. Food Chem. Toxicol. 34:131-145.

LeBars, D., and J. C. Gripon. 1989. Specificity of plasmin towards bovine alpha-S2-casein. J. Dairy Res. 56:817-821.

Maeno, M., N. Yamamoto, and T. Takano. 1996. Identification of an anithyprtensive peptide from casein hydrolysate produced by a proteinase from Lactobacillus helveticus CP790. J. Dairy Sci. 79:1316-1321.

Mara, O., C. Roupie, A. Duffy, and A. L. Kelly. 1998. The curd-forming properties of milk as affected by the action of plasmin. Int. Dairy J. 8:807-812

Maruyama, S., H. Mitachi, H. Tanaka, N. Tomizuka, and H. Suzuki. 1987. Studies on the active site and antihypertensive activity of angiotensin I-converting enzyme inhibitors derived from casern. Agric. Biol. Chem. 51:1581-1586.

McSweeney, P. L. H., N. F. Olson, P. F. Fox, A. Healy, and P. Hojrup. 1993. Proteolytic specificity of plasmin on bovine alpha-S1-casein. Food Biotechnol. 7:143-158.

Michaeli, A., and J. Feitelson. 1995. Reactivity of singlet oxygen toward large peptides. Photochem. Photobiol. 61:255-260.

Michaeli, A., and J. Feitelson. 1997. Reactivity of singlet oxygen toward proteins: The effect of structure in basic pancreatic trypsin inhibitor and in ribonuclease A. Photochem. Photobiol. 65:309315.

Ollikainen, P., and K. Nyberg. 1988. A study of plasmin activity during ripening of Swiss-type cheese. Milchwissenschaft 43:497-499.

Pellegrini, A., C. Dettling, U. Thomas, and P. Hunziker. 2001. Isolation and characterization of four bactericidal domains in the bovine beta-lactoglobulin. Biochim. Biophys. Acta 1526:131-140.

Pihlanto-Leppala, A., P. Koskinen, K. Piilola, T. Tupasela, and H. Korhonen. 2000. Angiotensin I-converting enzyme inhibitory properties of whey protein digests: Concentration and characterization of active peptides. J. Dairy Res. 67:53-64.

Pihlanto-Leppala, A., T. Rokka, and H. Korhonen. 1998. Angiotensin I converting enzyme inhibitory peptides derived from bovine milk proteins. Int. Dairy J. 8:325-331.

Pripp, A. H., T. Isaksson, L. Stepaniak, and T. Sorhaug. 2004. Quantitative structure-activity relationship modelling of ACE-inhibitory peptides derived from milk proteins. Eur. Food Res. Technol. 219:579-583.

Saito, T., T. Nakamura, H. Kitazawa, Y. Kawai, and T. Itoh. 2000. Isolation and structural analysis of antihypertensive peptides that exist naturally in Gouda cheese. J. Dairy Sci. 83:1434-1440.

Silva, S. V., and F. X. Malcata. 2005. Caseins as source of bioactive peptides. Int. Dairy J. 15:1-15.

Silva, S. V., A. Pihlanto, and F. X. Malcata. 2006. Bioactive peptides in ovine and caprine cheeselike systems prepared with proteases from Cynara cardunculus. J. Dairy Sci. 89:3336-3344.

Singh, T. K., P. F. Fox, and A. Healy. 1997. Isolation and identification of further peptides in the diafiltration retentate of the watersoluble fraction of Cheddar cheese. J. Dairy Res. 64:433-443.

Stadtman, E. R. 2001. Protein oxidation in aging and age-related diseases. Ann. N. Y. Acad. Sci. 928:22-38.

Visser, F.-M. W., and A.-E. A. Groot-Mostert. 1977. Contribution of enzymes from rennet, starter bacteria and milk to proteolysis and flavour development in Gouda cheese. IV. Protein breakdown: A gel electrophoretical study. Neth. Milk Dairy J. 31:247-264.

Visser, S., K. J. Slangen, A. C. Alting, and H. J. Vreeman. 1989. Specificity of bovine plasmin in its action on bovine alpha-S2casein. Milchwissenschaft 44:335-339.

Wiking, L., and J. H. Nielsen. 2004. The influence of oxidation on proteolysis in raw milk. J. Dairy Res. 71:196-200. 